\title{
KARAKTERISTIK SIFAT MEKANIK KOMPOSIT SERAT BAMBU RESIN POLYESTER TAK JENUH DENGAN FILLER PARTIKEL SEKAM
}

\author{
Agus Budiman, Sugiman* \\ Jurusan Teknik Mesin, Fakultas Teknik, Universitas Mataram \\ Jl. Majapahit No. 62 Mataram Nusa Tenggara Barat, Kode Pos : 83125 \\ *Email: s.sugiman@unram.ac.id
}

\begin{abstract}
This paper presents the effect of volume fraction of rice husks on the mechanical properties of bamboo fiber/unsaturated polyester composites. The composite specimens were made from bamboo fiber with fixed volume fraction of $40 \%$ and rice husk particle as filler with volume fractions varied $0 \%, 10 \%, 20 \%$ and $30 \%$. Matrix used was unsaturated polyester resin. Bamboo fibers and rice husk were surface treated using alkali solution 4\% (by weight) for 2 hours. The manufacturing process of composite was using hand layup method. The specimens were tested in tension, bending and in impact loading. The results show that the addition of rice husk particles up to volume fraction of $20 \%$ does not result in a decrease of tensile strength, but after a volume fraction of $20 \%$, the tensile strength tends to decrease. In bending test, the rice husk volume fraction up to $20 \%$ increase the bending strength, but after that then it tends to decrease. However the bending modulus seems unaffected by the volume fraction of rice husk. Similar to the bending modulus, the impact strength is not significantly affected by the volume fraction of rice husk.
\end{abstract}

Keywords: bamboo fiber, rice husk particles, polyester, volume fraction.

\section{PENDAHULUAN}

Bambu merupakan tanaman yang cepat tumbuh dan mampu menyerap karbondioksida di udara. Bambu dapat dipanen 3-4 tahun (Amada et al., 1997). Bambu dapat digunakan untuk material teknik baik dalam kondisi utuh, bentuk strip dan serat (Nayak and Mishra, 2016). Serat bambu terdiri dari cellulose, hemicellulose dan lignin. Kandungan celulose dan hemicelulosa dalam bentuk holocelulosa dapat lebih dari 50\% (Jain et al., 1992). Serat bambu secara mekanik mempunyai kekuatan tarik yang tinggi (140-800 MPa), dan modulus elastisitas yang tinggi (33 GPa) dengan densitas yang rendah 0,6-0,8 $\mathrm{g} / \mathrm{cm}^{3}$ (Defoirdt et al., 2010). Sehingga kekuatan jenis dan modulus elastis jenis serat bambu sangat tinggi dan sebanding dengan serat glass.

Untuk menghasilkan komposit serat bambu yang baik, kadungan lignin dalam serat bambu harus dihilangkan karena menghasilkan ikatan antara serat dan matrik yang buruk. Literatur telah melaporkan beberapa metode perlakuan permukaan serat bambu, baik dengan larutan alkali, kombinasi larutan alkali, acetalisasi dan silanisasi (Lee et al., 2009; Chen et al., 2011) dan kombinasi larutan alkali, plasma dan ultraviolet (Ma et al., 2011), dan metode hidrotermal (Qian et al., 2015). Dari beberapa metode tersebut, metode perlakuan alkali pada konsentrasi rendah 4 - $6 \%$ selama 2 jam menghasilkan ikatan serat/matrik yang baik, dengan teknik yang sederhana dan relatif murah (Kumar et al., 2012).

Hibridisasi komposit merupakan usaha untuk meningkatkan sifat tertentu material komposit, seperti kekakuan dan kekuatan impaknya. Hibridisasi dapat dengan filler baik organik dan anorganik. Untuk filler organik, limbah pertanian seperti sekam padi mempunyai sumber yag melimpah dan mempunyai kandungan silika yang cukup tinggi (96\%) (Ismail et al., 1999). Literature melaporkan penggunaan sekam padi sebagai pengisi karet (Ismail et al., 1999), semen (Jauberthie et al., 2003), dan polipropilen (Siriwardena et al., 2001). Penggunaan sekam padi untuk filler komposit serat bambu masih jarang dilaporkan (sejauh sepengetahuan penulis). Tujuan paper ini adalah untuk mengetahui pengaruh fraksi volume serbuk sekam padi pada komposit serat bambu/polyester tak jenuh. Beberapa pengujian yang dilakukan adalah pengujian tarik, pengujian bending dan pengujian impak.

\section{METODELOGI PENELITIAN Material}

Adapun material yang digunakan dalam penelitian ini adalah serat bambu dengan panjang serat $25 \mathrm{~mm}$. Serbuk sekam padi dengan ukuran lolos ayakan (saringan) 40 mesh. Larutan $\mathrm{NaOH}$ dengan konsentrasi $4 \%$ (berat). Sedangkan sebagai matrik adalah resin polyester tak jenuh, Yucalak 157 BQTN, 
dengan katalis metil eter keton peroksida (MEKPO).

\section{Persiapan Spesimen}

Perlakuan permukaan untuk serat bambu dan sekam masing-masing dilakukan dengan merendamnya (dalam tempat terpiah) dengan larutan $\mathrm{NaOH}$ fraksi volume $4 \%$ (berat) selama 2 jam pada suhu $29^{\circ} \mathrm{C}$. Setelah perendaman, serat dan sekam dibilas dengan air sampai bersih (tidak berlendir), dan kemudian dikeringkan.

Sebelum resin dan serat dicetak, pada cetakan diolesi dengan kit black magic (sebagai release agent) untuk memudahkan pengambilan spesimen dari cetakan kemudian dibiarkan kering. Setelah itu, resin dan katalis dicampur dengan perbandingan 100:1 (berat) dalam gelas pencampur dan diaduk sampai homogen. Serat dan sekam dimasukan dalam ember sesuai fraksi volume masing-masing dan diaduk agar campuran mengikuti standar ASTM D256. Pengujian tarik menggunakan alat uji tarik universal testing machine merk Control type (C0820/C) dengan kapasitas 2000 kN. Pengujian bending menggunakan alat uji bending merk CBR Tester, sedangkan pengujian impak menggunakan alat uji impak type RMU Testing Equipment Serial A052. Uji scanning elektrom microscope (SEM) dilakukan pada permukaan patahan specimen uji tarik menggunakan alat SEM type Zeiss EVO MA 10.

\section{HASIL DAN PEMBAHASAN \\ Kekuatan tarik}

Gambar 1(a) menunjukkan tipikal kurva stress-displacement hasil pengujian tarik komposit serat bambu-sekam padi/polyester tak jenuh. Terlihat kemiringan kurva daerah linier cenderung meningkat dengan bertambahnya fraksi volume sekam padi dari fraksi volume 10\%-30\%. Hal ini menunjukkan

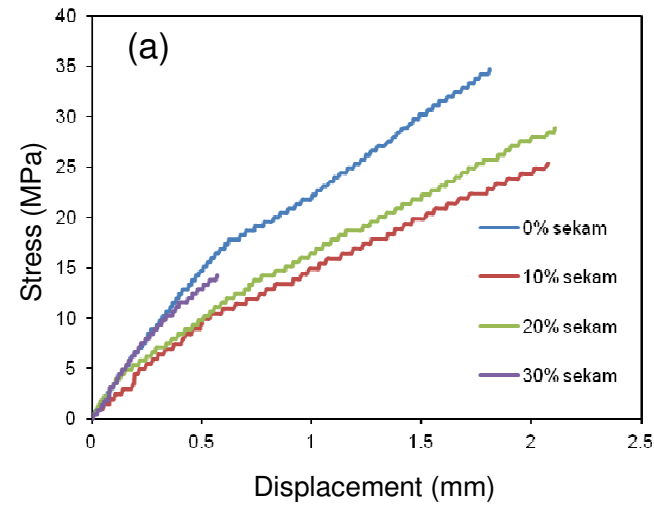

Gambar 1. (a) Tipikal grafik stress-displacement, komposit serat bambu polyester sekam padi

merata. Resin dituangkan ke dalam cetakn yang telah berisi dengan serat dan sekam. Campuran serat, sekam dan resin kemduian dipress dengn plat baja selama 2 jam pada suhu kamar. Fraksi volume serat bambu dibuat tetap sebesar $40 \%$, sedangkan fraksi volume sekam padi bervariasi; 0, 10\%, 20\% dan $30 \%$.

\section{Pengujian Mekanik}

Pengujian mekanik terdiri dari tiga pengujian yaitu uji tarik, uji bending dan uji impak. Spesimen uji tarik mengikuti standar ASTM D3039, spesimen uji bending mengikuti standar ASTM D790, dan spesimen uji impak

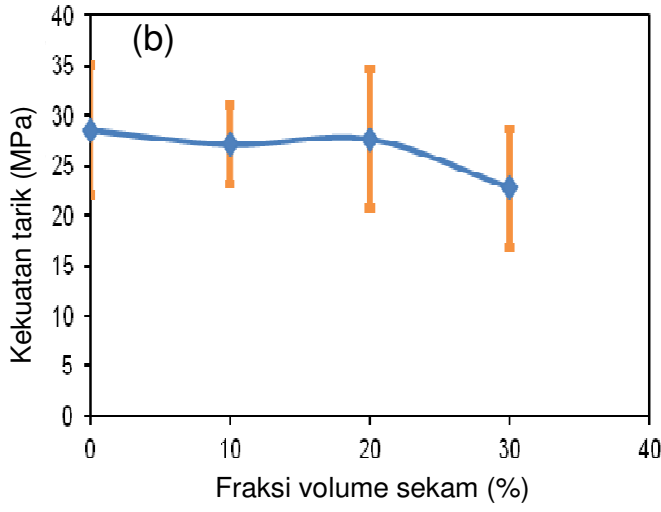

(b) Grafik hubungan kekuatantarik

bahwa pada rentang fraksi volume tersebut, meningkatnya fraksi volume sekam padi cenderung meningkatkan kekakuan komposit. Namun kemiringan (kekakuan) kurva stressdisplacement untuk komposit tanpa sekam justru sama dengan pada fraksi volume 30\%. Hal ini disebabkan mungkin pada fraksi volume $10 \%-30 \%$, kekakuan disumbangkan oleh peningkatan kekakuan matriks akibat penambahan material sekam, sedangkan pada tanpa sekam ikatan antara serat bambu dengan matriks lebih baik dari penambahan material sekam sehingga menghasilkan kekakuan yang tinggi pula. 

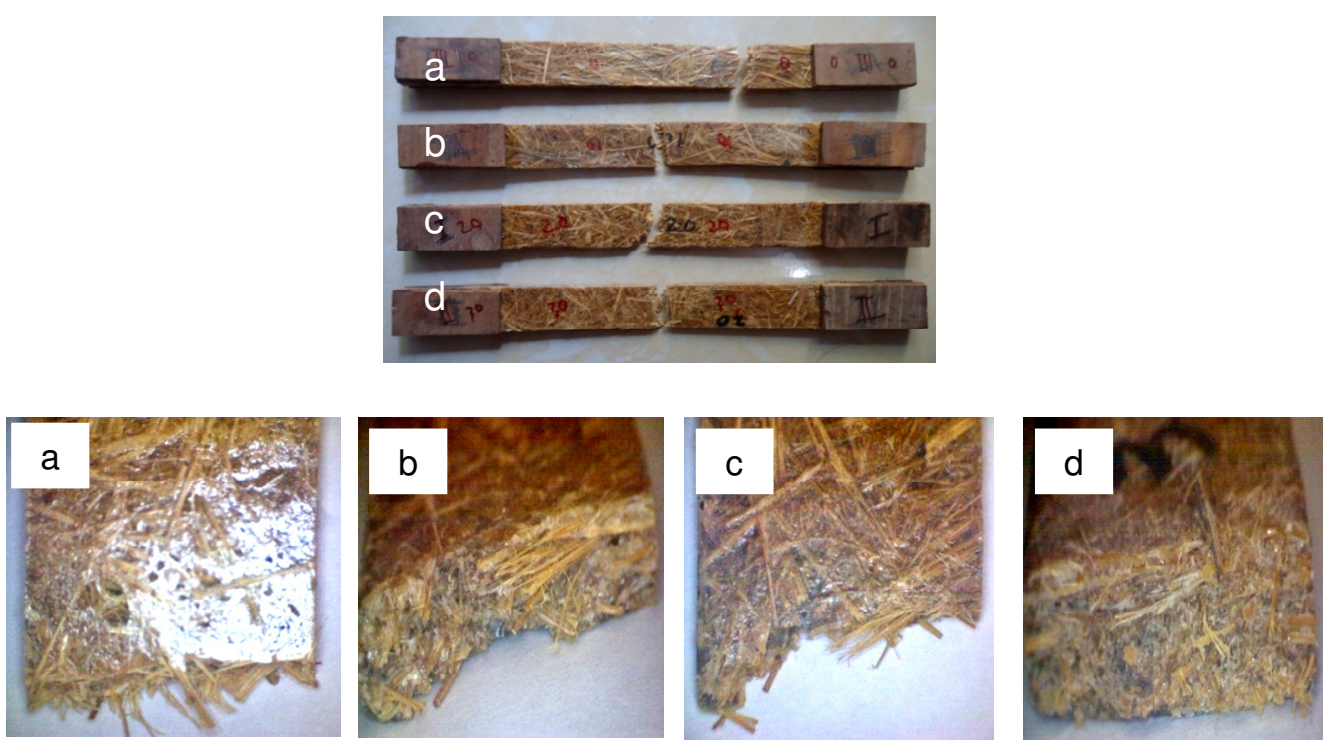

Gambar 2. Foto kegagalan spesimen uji tarik komposit serat bambu polyester untuk fraksi volume sekam padi (a) $0 \%$, (b) $10 \%$, (c) $20 \%$ and (30\%). Perbesaran gambar 50x

Gambar 1(b) menunjukkan kekuatan komposit serat bambu-sekam padi/polyester tak jenuh dengan fraksi volume. Terlihat bahwa kekuatan tarik cenderung konstan sampai fraksi volume sekam $20 \%$ dan

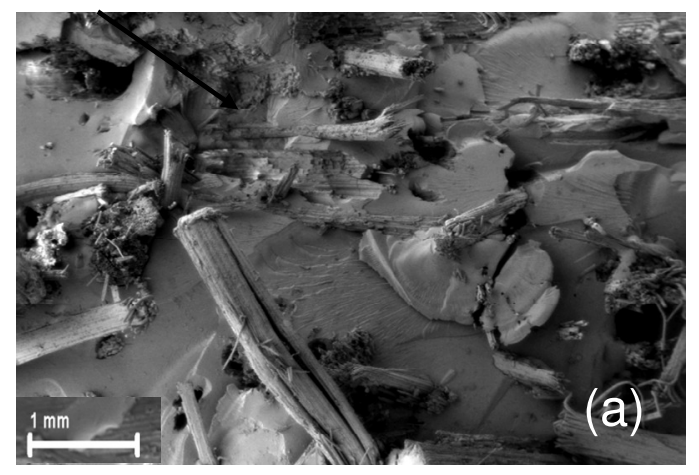

resin untuk berikatan secara sempurna dengan serat bambu.

Gambar 2 menunjukkan foto komposit serat bambu polyester dengan filler partikel sekam padi yang telah diuji tarik. Patahan dari

Gambar 3. Foto SEM permukaan patah uji tarik komposit serat bambu/polyester (a) tanpa sekam, (b) dengan filler sekam padi pada fraksi volume $20 \%$.

kemudian cenderung menurun setelah fraksi volume tersebut. Penurunan yang terjadi pada kekuatan tarik komposit serat bambu tersebut mungkin disebabkan oleh kandungan partikel sekam yang ada mampu menghalangi

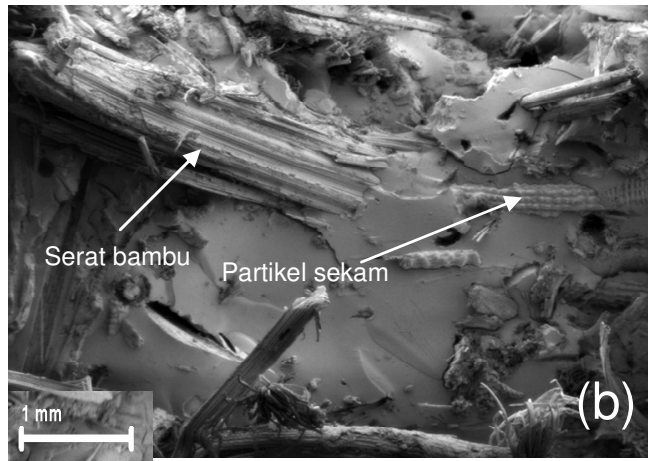

setiap spesimen berbeda-beda, yang mungkin disebabkan oleh penambahan filler sekam padi. Untuk spesimen dengan fraksi volume sekam $0 \%$ bentuk patahannya terlihat sedikit serabut serat yang memanjang pada permukaan patahan. Hal ini terjadi karena 
serat dan resin mampu berikatan dengan baik. Berbeda dengan fraksi volume 10\%, $20 \%$ dan $30 \%$ sekam bentuk patahannya terlihat banyak serabut serat yang pendek pada permukaan patahan. Hal ini disebabkan karena serat dan resin tidak mampu berikatan dengan baik karena adanya partikel sekam yang menghalanginya sehingga bentuk patahan kelihatan serat tercabut antara permukaan yang satu dengan yang lainnya, seperti terlihat pada gambar 3 .

\section{Kekuatan Bending}

Gambar 4(a) menunjukkan tipikal kurva beban-displacement komposit serat bambu dengan filler partikel sekam akibat beban bending. Sebagian besar kurva menunjukkan adanya daerah elastis dan daerah plastis.
Hal ini menunjukkan bahwa pengaruh filler efektif sampai fraksi volume $20 \%$, setelah itu karena kemungkinan filler menghalangi ikatan serat bambu dengan polyester, sehingga menyebabkan penurunan kekuatan bending.

Pada gambar 4(c) terlihat hamburan data sehingga pengaruh fraksi volume terhadap modulus bending tidak signifikan. Efek filler bersifat meningkatkan kekakuan matrik, tetapi jika semakin banyak dapat menghalangi ikatan serat dan matrik, sehingga efeknya menjadi negatif. Kompetisi efek positif peningkatan kekakuan matrik dan efek negatif mengurangi ikatan serat dengan matrik kemungkinan sampai fraksi volume $30 \%$ masih berimbang, sehingga menyebabkan modulus bending yang hampir konstan.
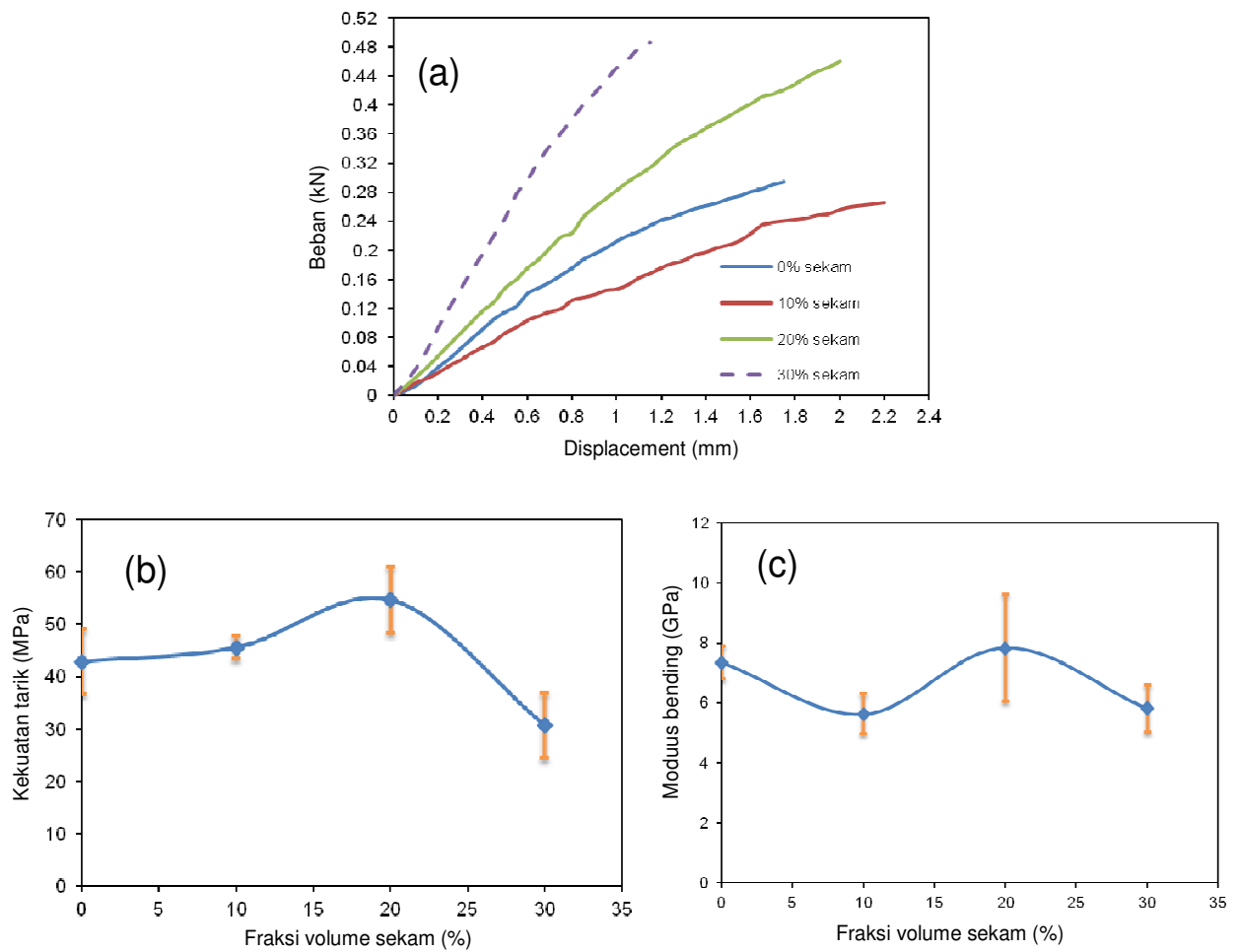

Gambar 4. (a) Kurva beban-displacement komposit serat bambu polyester sekam padi

Deformasi plastis mendominasi kurva bebandisplacement untuk semua fraksi volume sekam. Terlihat juga bahwa komposit langsung patah setelah beban puncak tercapai. Sedang pada gambar 4(b) terlihat bahwa kekuatan bending cenderung naik sampai fraksi volume $20 \%$ sekam, kemudian cenderung menurun setelah fraksi volume itu. (b) kekuatan bending, (c) Modulus bending

Gambar 5 menunjukkan kondisi spesimen setelah pengujian bending. Untuk fraksi volume sekam $0 \%$, terjadi retakan pada bagian bawah spesimen dan kemudian menjalar ke atas tetapi tidak tegak lurus ketebalan spesimen. Hal ini terjadi juga pada spesimen dengan fraksi volume sekam $10 \%$, tetapi beban puncak lebih rendah daripada 
spesimen fraksi volume sekam 0\%. Hal tersebut kemungkinan besar disebabkan ketebalan spesimen yang lebih rendah sehingga nilai inersianya lebih rendah dibanding fraksi volume sekam $0 \%$. Sementara untuk fraksi volume sekam $20 \%$ karena lemahnya ikatan antar serat dan matrik. Pada fraksi volume sekam $30 \%$, terlihat terjadi fiber pulled out pada patahan dan sebagai jembatan retak patahan spesimen.
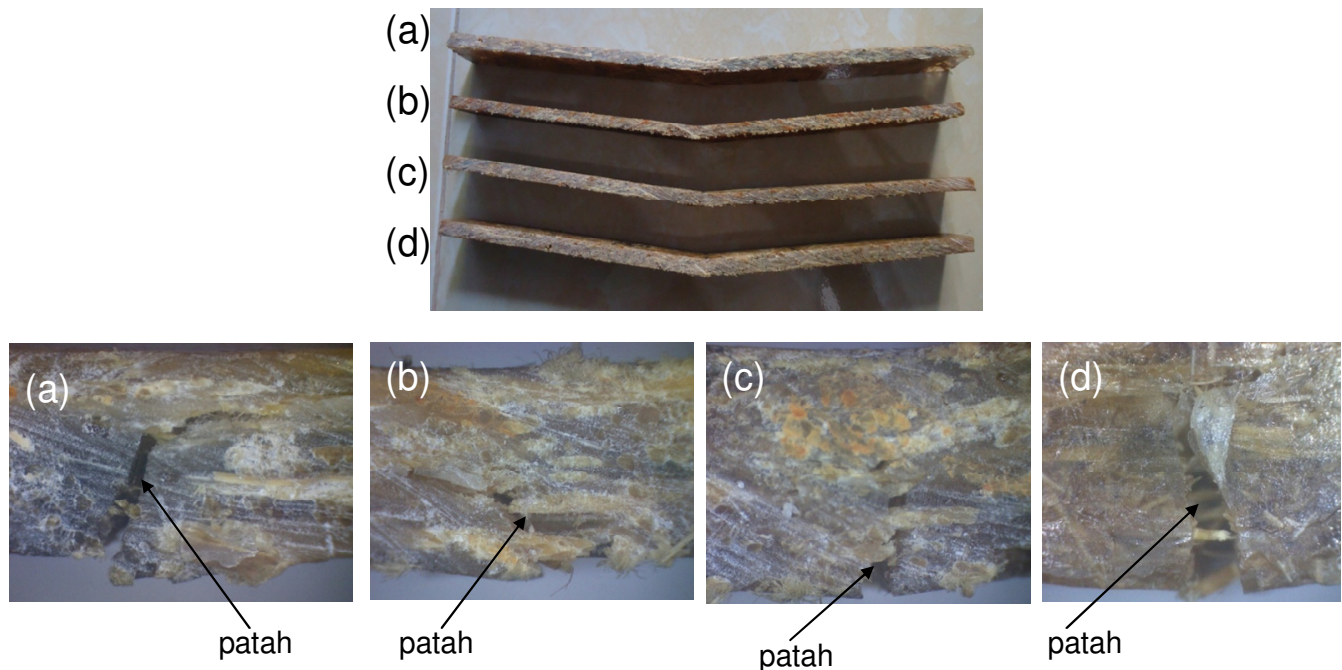

Gambar 5. Foto kegagalan spesimen uji bending komposit serat bambu polyester untuk fraksi volume sekam padi (a) $0 \%$, (b) $10 \%$, (c) $20 \%$ and (30\%). Perbesaran gambar 50x

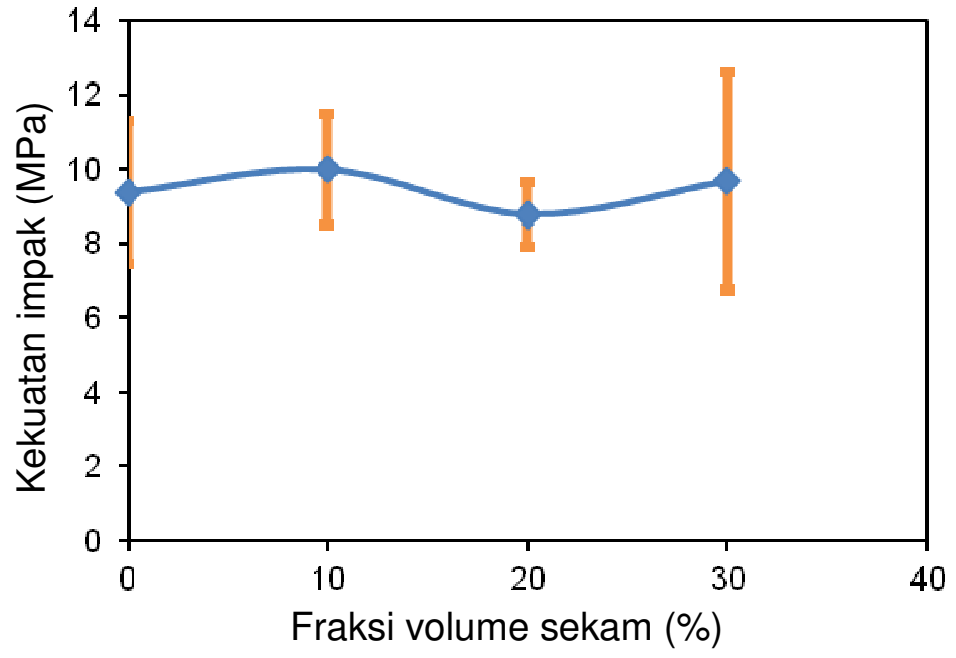

Gambar 6. Hubungan kekuatan impak komposit serat bambu polyester sekam padi terhadap fraksi volume sekam

dan $30 \%$, terjadi retakan dari bawah dan kemudian merambat hampir tegak lurus ketebalan spesimen. Hal ini menunjukkan bahwa material nampak lebih getas atau

\section{Kekuatan Impak}

Gambar 6 menunjukkan grafik kekuatan impak dengan fraksi volume sekam padi komposit serat bambu/polyester tak 
jenuh. Terlihat bahwa terjadi hamburan data yang besar untuk semua fraksi volume sekam, sehingga pengaruh fraksi volume sekam cenderung tidak signifikan pada kekuatan impak.

Pada gambar 7 menunjukkan bahwa, komposit serat bambu dengan filler partikel sekam mempunyai patahan yang hampir sama yaitu patah di bagian tengah dan cenderung bersifat getas. Spesimen secara keseluruhan mengalami patah getas di bagian yang dikenakan beban impak. Pada beberapa hasil pengujian impak didapatkan bahwa menurun. Fraksi volume sekam padi tidak berpengaruh singifikan pada modulus bending. Meningkatnya fraksi volume sekam padi juga tidak menunjukkan pengaruh yang signifikan pada kekuatan impak.

\section{DAFTAR PUSTAKA}

Amada S., Ichikawa Y., Munekata T., Nagase Y., Shimizu K., (1997), Fiber texture and mechanical graded structure of bambu. Composites Part B 28, pp. 13-20.

Chen H., Miao M., Ding X., (2011), Chemical treatments of bamboo to modify its
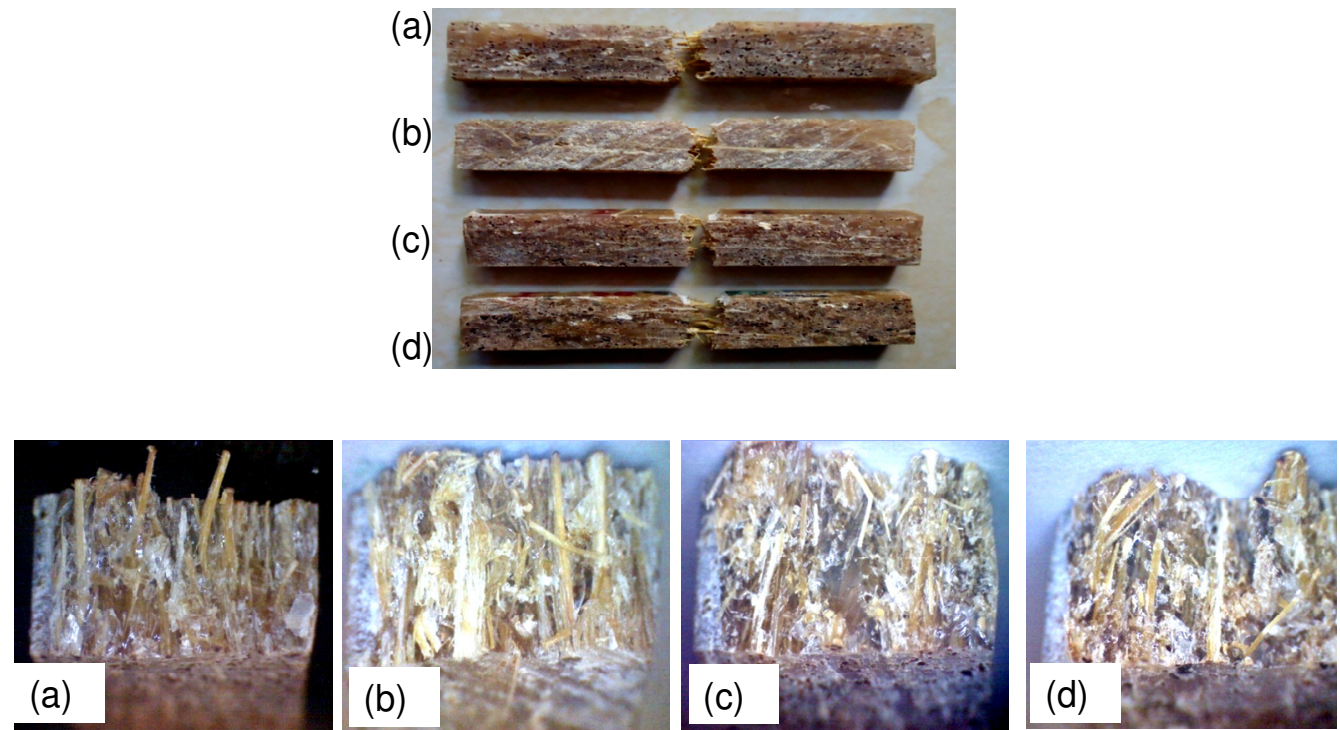

Gambar 7. Foto kegagalan spesimen uji impak komposit serat bambu polyester untuk fraksi volume sekam padi (a) $0 \%$, (b) $10 \%$, (c) $20 \%$ and (30\%). Perbesaran gambar 50x

kegagalan tidak selalu terjadi pada daerah yang secara langsung terkena tumbukan, melainkan pada bagian lain yang mengalami cacat.

\section{KESIMPULAN}

Investigasi tentang pengaruh fraksi volume sekam padi pada sifat mekanik komposit serat bambu-sekam padi/polyester tak jenuh telah dilakukan. Kekuatan tarik cenderung konstan dengan meningkatnya fraksi volume sekam padi sampai $20 \%$, tetapi setelah itu menunjukkan penurunan. Jenis kegagalan yang terjadi pada spesimen uji tarik yaitu patah getas. Kekuatan bending cenderung meningkat dengan meningkatnya fraksi volume sekam padi sampai $20 \%$, namun setelah itu kemudian cenderung moisture absorption and adhesion to vinyl ester resin in humid environment, Journal of Composite Materials 45(14), 1533-1542.

Defoirdt N., Biswas S., De Vriese L., Tran L.Q.N., Van Acker J., Ahsan Q., Gorbatikh L., Van Vuure A., Verpoest I., 2010, Assessment of the tensile properties of coir, bambu and jute fibre, Composites: Part A 41, pp. 588-595.

Ismail H., Nasaruddin M.N., Ishiaku U.S., 1999, White rice husk ash filled natural rubber compounds: the effect of multifunctional additive and silane coupling agents. Polymer Testing 18, 287-298.

Jain S., Kumaru R., Jindal U.C., 1992 , Mechanical behaviour of bambu and 
Bambu composite, Journal of Materials Science 27, 4598-4604.

Jauberthie R., Rendell F., Tamba S., Cisse I.K., 2003, Properties of cement-rice husk mixture Frank Construction and Building Materials 17, 239-243.

Kang J.T., Park S.H., Kim S.H., 2014, Improvement in the adhesion of bambu fiber reinforced polylactide composites, Journal of Composite Materials 48(21), 2567-2577.

Kumar V., Kumar R., 2012, Dielectric and mechanical properties of alkali- and silane-treated bambu-epoxy nanocomposites. Journal of Composite Materials 46(24), 3089-3101.

Lee S.Y., Chun S.J., Doh G.H., Kang I.A., Lee S., Paik K.H., 2009, Influence of chemical modification and filler loading on fundamental properties of bambu fibers reinforced polypropylene composites Journal of Composite Materials 43(15), 1639-1657.
Ma H., Joo C.W., 2011, Influence of surface treatments on structural and mechanical properties of bambu fiberreinforced poly(lactic acid) biocomposites, Journal of Composite Materials 45(23), 2455-2463.

Nayak L., Mishra S.P., 2016, Prospect of bambu as a renewable textile fiber, historical overview, labeling, controversies and regulation, Fashion and Textiles 3(2), 1-23.

Qian S., Wang H., Zarei E., Sheng K., 2015, Effect of hydrothermal pretreatment on the properties of moso bambu particles reinforced polyvinyl chloride composites. Composites Part B 82, 2329.

Siriwardena S., Ismail H., Ishiaku U.S., 2001, Effect of mixing sequence in the preparation of white rice husk ash filled polypropylene/ethylene-propylenediene monomer blend, Polymer Testing $20,105-113$. 